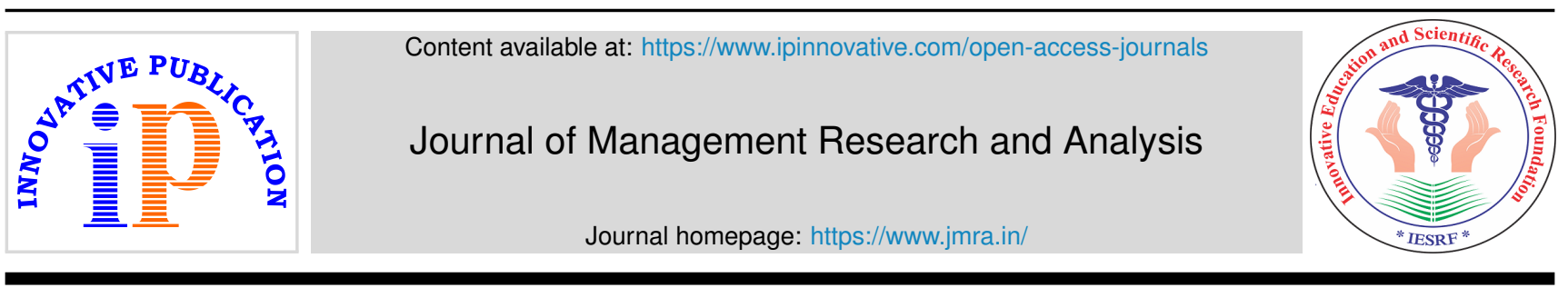

\title{
Editorial
}

\section{Moonlighting - Is it a challenge to healthy organizational environment?}

\author{
Thankachan Jose Kaitharath ${ }^{1, *}$ \\ ${ }^{1}$ Principal, Christ Institute of Management, Rajkot, Gujarat, India
}

\section{A R T I C L E I N F O}

Article history:

Received 19-4-21

Accepted 26-4-21

Available online 02-05-2021 (c) This is an open access article distributed under the terms of the Creative Commons Attribution License (https://creativecommons.org/licenses/by/4.0/) which permits unrestricted use, distribution, and reproduction in any medium, provided the original author and source are credited.
Human beings are constantly thriving for security and satisfaction in every aspect of their life. We, being socially dependent on each other, have to rely on others as much as ourselves for fulfillment of these needs, because that is the environment we have been brought up in. An aspectthat has existed always yet surfaced majorly due to recent hit of COVID-19 pandemic and which needs to be addressed is the sense of professional security and how it affects the employees' action and an organization as its result. Moonlighting, a practice of working a second job outside normal business hours, is one such phenomenon that tends to take place due to job insecurity, want of more income and dissatisfaction. The question ishow it affects the employee and the employer. If dissected from an employee's point of view, he is surviving and dependent on a highly volatile environment and more so, recently. Such a level of uncertainty is always a trigger that leads one to moonlight and search for jobs apart from their primary jobs in order to earn more money, secure himself and his family. Furthermore, as said earlier, every employee is constantly looking for security and satisfaction from the employer in terms of motivation, assurance, career development, skill enhancement and acknowledgment. Lack of all these elements from the organization one is working for, can cause the employees to search for alternative paths where he might achieve this.

\footnotetext{
* Corresponding author.

E-mail address: dr.kjthankachan@gmail.com (T. J. Kaitharath).
}

When observed from an employer's point of view, a fight for survival in a turbulent environment as discussed earlier takes place within the organization as well. In such a scenario, an organization would want a completely dedicated employee for itself. Especially, with extensive globalization and digitalization of our economy, the pressure on organizations is high and their need to have a goal-oriented workforce with focus on organization specific objectives is also completely justified. Consequently, most of the organizations have already implemented rules against dual employment in their employment contract. But the question still stands; is moonlighting a necessity or distraction?

The answer to this question is mere a matter of perception. For an employee who is in search of motivation and security in any form from the employer, the degree of satisfaction completely depends upon the external factors he is surrounded by and internal factors he is within which does not necessarily imply the failure of an organization to look after their employees and provide a 360-degree job satisfaction and security as a result. Similarly, despite all the efforts of an organization if a member of their team opts to also pursue an alternate job, it would be wrong to insinuate that the particular individual lacks organizational commitment and would be any less dedicated towards his organizational objectives. Instead, he might just be looking for an alternate source of income to fortify his stand in this turbulent environment. 
However, with increased uncertainty of the political and economical environment in our country, moonlighting has increased considerably in the last few years. Especially, in the midst of COVID-19 pandemic, the insecurity regarding the future has caused a lot of chaos in the employment market which has proportionately increased hours of moonlighting as well. Undoubtedly, it gives a sense of satisfaction and fulfillment to the employees, as it aids in increased monetary benefits, personal and professional growth. But as excess of anything has its side-effects, logging extra hours into moonlighting has its own, towards employees as well as employers. It might lead to excessive multi-tasking, exhaustion and thereby, decreased efficiency and productivity among the employees. This would directly affect all the tasks they are responsible for in the long run as well as have a negative effect on their health. Thus, negating the very benefit, they started moonlighting for. Similarly, as said earlier, moonlighting among the employees in moderation does not affect the effectiveness of an organization. But when it crosses the threshold, it starts influencing the very core of the organization on which its success depends, the system and the goals. Overly multitasking employees tend to have lot of responsibilities to take care of which might cause them to be distracted from the organizational objectives resulting in low performance and low focus. Also, it indirectly affects the team they are working with emotionally and physically. Thereby, bringing about a reduction in the overall productivity of the organization.

According to Maslow's hierarchy of needs, every individual is governed by various motivating factors categorized into five groups. Lack of any of the motivational factors among them might lead to finding an alternate path to achieve those. Professionally, an individual seeks to fulfill, firstly their safety needs and thereafter, the self-esteem and self-actualization needs. A sense of unavailability among these three factors can cause an individual to moonlight. Hence, it is not realistic and practical to completely ban moonlighting as it might give rise to exactly opposite results as one intended to obtain. For instance, imposing strict regulations on moonlighting might not go well with certain employees as it would seem like interfering with their off-duty time or their ability to meet their economic, social or career needs. This would in turn increase the employee attrition rate in the organization and put forward a bad reputation of the organization.

A far better option would be implementing strict moonlighting policies, thus, providing a leeway for both the employees and organization to satisfy their needs and work with it without affecting none negatively. Some examples of such restrictions include prior notice to the employer regarding the second job, periodic employee evaluation and the regulations for satisfying the demands of first job prior to the second job; prohibiting any work that would cause conflict of interest, interferes with the employee's schedule, contributes other health and safety issues, or exposes proprietary information to or otherwise advances the interests of a competitor. Thus, looking at the bigger picture, any work which does not interfere with the job performance of the employee and organization's efficacy will not be discouraged. These techniques, in the long run, would help in maintaining a synergy between the organization and the employee in terms of moonlighting.As quoted by Harvey Mackay, an American Businessman "."

\section{Author biography}

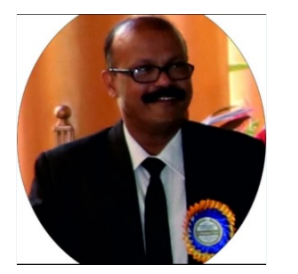

Thankachan Jose Kaitharath, Principal

Cite this article: Kaitharath TJ. Moonlighting - Is it a challenge to healthy organizational environment?. J Manag Res Anal 2021;8(1):1-2. 